\title{
Evaluation of incorporation of bone allograft at the site of implantation in various clinical conditions along with its complications
}

\author{
Laxmi Narayan Jajoriya ${ }^{1 *}$, Sumit Sural ${ }^{2}$
}

\begin{abstract}
${ }^{1}$ Department of Orthopaedic, Geetanjali Medical College and Hospital, Udaipur, Rajasthan, India
${ }^{2}$ Department of Orthopaedic, Maulana Azad Medical College, New Delhi, India
\end{abstract}

Received: 11 March 2020

Revised: 10 May 2020

Accepted: 12 May 2020

\author{
*Correspondence: \\ Dr. Laxmi Narayan Jajoriya, \\ E-mail: laxminarayan200810@gmail.com
}

Copyright: () the author(s), publisher and licensee Medip Academy. This is an open-access article distributed under the terms of the Creative Commons Attribution Non-Commercial License, which permits unrestricted non-commercial use, distribution, and reproduction in any medium, provided the original work is properly cited.

\begin{abstract}
Background: Bone transplants have been used routinely in the present century for diverse purposes to unite fractures, fuse joints, and repair skeletal defects.

Methods: Twelve patients with fracture, bone defect, deformity, difficulty in the fusion of bone, etc. were taken in the study for elective surgery with fresh frozen allograft in the orthopedics department with the incorporation of inclusion and exclusion criteria.

Results: Out of 12 cases in this study, 7 cases were related to spinal fusion, 3 cases were of fractures with bone defects, 1 case of non-union neck femur fracture and 1 case was of revision hip arthroplasty with the acetabular bone defect. Seventy-five percent (9 patients) and 25\% (3 patients) were graded fair and poor respectively in the preoperative phase. At 6 months, excellent results were obtained in 50\% (6 patients), good in 25\% (3 patients), fair in $25 \%$ ( 3 patients), while none were graded as poor in terms of clinical evaluation.

Conclusions: Fresh frozen bone, a good source of abundant bone allograft, can be stored in $-70^{\circ}$ freezer for use in orthopedic surgery to fill any filling defect in the bone. Also, proper storage, better surgical technique, hospital infection control policy, antibiotic policy, preoperative use of antibiotics before surgery has a good clinical outcome.
\end{abstract}

Keywords: Bone allograft, Spinal fusion, Non-union, Morselized, Fracture

\section{INTRODUCTION}

Bone grafts are used for healing of fractures and arthrodesis, filling of cystic defects, and for the bridging of skeletal defects after traumatic loss or ablation of tumors.

Allogenic bone can be machined and separated into cortical, cortico-cancellous, and cancellous preparations. Cortical and cortico-cancellous allografts are used for structural support. They have limited osteoconductive capability and no osteoinductive properties. Cortical and cortico-cancellous bone grafts undergo slow resorption in the host due to limited vascular invasion causes decreases in the structural strength of the graft. The cortical/ corticocancellous allograft is incorporated by the host through creeping substitution in conjunction with slow bone remodelling.

Bone transplants have been used routinely in the present century for diverse purposes to unite fractures, fuse joints, and repair skeletal defects. This has been possible since graft incorporation occurs successfully in a large percentage of cases.

Bone grafts are used in a variety of orthopedic procedures like to fill cavities or defect following curettage of cysts and benign tumors, to bridge major defects and restore 
continuity of long bones following trauma, infection or tumor resection, to promote union in cases of nonunion and delayed union, reconstructive surgeries for revision of total hip and knee arthroplasties, skeletal defect as a result of congenital pseudoarthrosis and arthrodesis of various joints, including spine. ${ }^{1}$

Allografts provide the advantages of availability without morbidity at the donor site, but the manner in which they are processed will influence their biological, immunological, and biomechanical properties.

Most allografts used are fresh, deep-frozen; freeze-dried and in some instances may be partially demineralized., ${ }^{2,3}$

Freeze-drying/lyophilization is a process that allows maximum removal of water using liquid nitrogen at $169^{\circ}$ C. Sterilization is done using ethylene oxide. Grafts are then kept in a freeze dryer with chamber vacuum at $60^{\circ} \mathrm{C}$ to $-70^{\circ} \mathrm{C}$ for 14 to 16 days. They are then warmed to room temperature and stored in sterile glass containers sealed under vacuum at the same temperature. Before freeze-dried allograft can be used. They must be rehydrated by immersion in saline. ${ }^{4,5}$ It is an excellent method of storage of bone and freeze-dried tissues that may be stored for many years at room temperature, using vacuum-packed bottles. Freeze drying also reduces the antigenicity of bone. However, the equipment used for freeze-drying is expensive and requires close monitoring, especially ethylene oxide that is commonly used for sterilizing the freeze-drying chamber. A significant change in biochemical properties has been observed after freeze drying. ${ }^{6}$

All bone grafts proceed through the different phases i.e. phase of inflammation, phase of revascularisation, phase of osteoinduction, phase of osteoconduction, and phase of remodelling. ${ }^{7}$

This prospective study on fresh frozen allografts was conducted to evaluate the results of incorporation of the bone graft as well as to assess for any infection or reactions associated with it.

\section{METHODS}

This was a type of prospective study. Due to the limited duration and minimum six months post-operative followup, 12 patients who underwent elective surgery with fresh frozen bone allograft in the Department of Orthopaedic Surgery, Lok Nayak and associated Hospitals, New Delhi from October 2014 to April 2016 were selected for this study as per the inclusion and exclusion criteria given below.

Inclusion criteria of recipient patients, above 4 years age. Bone grafting is done for any of the following indications non-union of fractures of long bones, posterolateral spinal fusion in spondylolisthesis and, spinal trauma, cervical laminoplasty. Exclusion criteria for recipient patients, benign bone tumors treated by curettage and bone grafting, infected non-union, non-union due to pathological fracture, congenital pseudoarthrosis of tibia, immunocompromised state (HIV, uncontrolled diabetes mellitus, malignancy), patient on antibiotics for any other reason (endocarditis prophylaxis), and destitute and homeless patients.

\section{Criteria for donors of bone allograft}

Femoral head of patients underwent hemiarthroplasty and total hip arthroplasty. Also bone slices from patients with total knee arthroplasty. Bone graft donors should not have HIV, hepatitis B or hepatitis C, any malignancy, any systemic, local or, sexually transmitted diseases, or any blood dyscrasias or blood pathologies. The graft should not suspect to be infected or contaminated. Immediately after harvesting the graft, the swab was taken for culture if growth present, the graft was discarded. The graft was washed with normal saline and stored in an autoclaved stainless-steel container in a sterile latex glove containing gentamicin impregnated saline solution $(320 \mathrm{mg}$ in $100 \mathrm{ml}$ saline). The graft was immediately transferred to a deep freezer where it was frozen to a temperature of $-70^{\circ} \mathrm{C}$.

All patients included in the study were tested for intradermal sensitivity test to cefazolin, the basic preanesthetic check-up along with the routine investigations along with CRP, ESR, bone biopsy, ECG, etc. Written informed consent was obtained from all patients planned for surgery.

All patients undergoing bone grafting received injection Cefazolin $1 \mathrm{gm}$ i.v. 30 minutes prior to skin incision. Allograft thawed in warm saline solution for grafting with removing all soft tissue and cartilage, cut in the desired shape, or morselized as per need (Table 4, Figure 5). The graft was thoroughly washed in saline before transplanting. The surgical site was also washed with copious saline. Surgical time and blood loss were recorded.

Postoperatively axillary temperature charting, antibiotic prophylaxis with cefazolin till postoperative day 2, ESR, and CRP charting, routine wound inspection was made. A suction drain was removed on postoperative day 2. In case of fever or any drainage from the surgical site up to suture removal, discharge sample was sent for gram staining, culture, and sensitivity pattern. Patients were instructed to report for suture removal on the $14^{\text {th }}$ day.

Follow up in all cases was done for wound inspection, history of fever, the sign of inflammation, routine investigation if needed along with CRP, and ESR. The patient was followed up only at 2 weeks, 6 weeks, 3 months, and 6 months in case of no complications such as an episode of fever, inflammation signs, discharge from the surgical site, etc. Plain radiograph of the operated area, CT scan of the operated area for graft incorporation, if 
required at 6 months and HIV I and II, anti-HBsAg, antiHCV were done at 6 months.

Data analysis was carried out using SPSS v22. All tests were done at alpha (level significance) of 5\%; means a significant association present if the $\mathrm{p}$ value was less than 0.05 .

\section{RESULTS}

Out of 12 cases in this study, 7 cases were related to spinal fusion, 3 cases were of fractures with bone defects, 1 case of non-union neck femur fracture and 1 case was of revision hip arthroplasty with the acetabular bone defect.

Out of 7 cases of spinal fusion, 3 cases were of unstable vertebral fractures (1 each of T12, L1 and L4), one case of cervical laminoplasty (C3-C4-C5), one case L4-L5 and L5-S1 spondylolisthesis, one case of posterior fusion in post tubercular kyphotic deformity T12-L1 level and one case of second stage anterior interbody fusion L2-L3 tuberculosis (Figure 1).

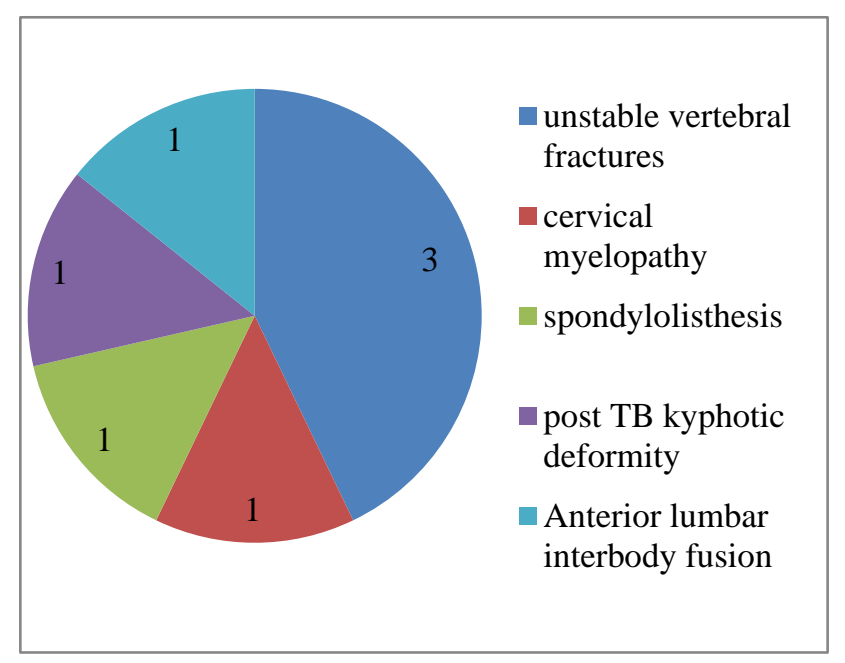

Figure 1: Bone allograft in spinal fusion.

In this study, bone allograft was used in four cases of fracture. Two cases each were of 4 weeks old comminuted intertrochanteric fracture femur. In one case of depressed type fracture, tibial plateau structural bone allograft was used to elevate the depressed fracture fragment maintain articular integrity (Figure 2 and 3).

One case of nonunion fracture neck of the femur with implant failure required revision of the implant with valgus osteotomy and bone allograft. On the follow-up period of this patient, there was a recurrence of failure of the implant with the persistence of nonunion of fracture neck femur.

Out of 12 cases in study 2 showed incorporation at 4 months, 3 showed incorporation at 5 months, and 5 in 6 months. The average time for consolidation was 5.3 months (Table 1).
Table 1: Time taken for graft incorporation.

\begin{tabular}{|lll|}
\hline S. no. & Time taken & Number \\
\hline 1. & 4 months & 2 \\
\hline 2. & 5 months & 3 \\
\hline 3. & 6 months & 5 \\
\hline
\end{tabular}

Out of 11 cases included in this study, only one case $8.33 \%$ got infected postoperatively (Table 2).

Table 2: Infection rate.

\begin{tabular}{|lll|}
\hline Variables & $\mathbf{N}$ & $\%$ \\
\hline No infection & 11 & 91.67 \\
\hline Infection & 1 & 8.33 \\
\hline Total & 12 & 100 \\
\hline
\end{tabular}

In this study, the mean ESR value of the cases was 16.75 preoperatively and 13.2 at the end of 6 months. Similarly, mean CRP preoperatively was 6.82 and was 5.16 at 6 months (Table 3).

Table 3: Mean ESR and mean CRP.

\begin{tabular}{|lll|}
\hline Time period & $\begin{array}{l}\text { Mean ESR of } \\
\text { patients }\end{array}$ & $\begin{array}{l}\text { Mean CRP of } \\
\text { patients }\end{array}$ \\
\hline Pre-operative & 16.75 & 6.82 \\
\hline Day-2 & 32.78 & 24.89 \\
\hline Day-14 & 31.05 & 16.3 \\
\hline 6 weeks & 25.5 & 13.13 \\
\hline 3 months & 21.33 & 10.14 \\
\hline 6 months & 13.2 & 5.16 \\
\hline
\end{tabular}

As per visual analog score (VAS), the results of excellent or good pain relief seen in $8(66.67 \%)$ patients at 6 weeks increased to $11(91.67 \%)$ patients at 3 months and 11 $(91.67 \%)$ also at 6 months, whereas one $8.33 \%$ case of implant failure with non-union fracture neck of the femur had poor pain relief at 3 months and was relieved by implant removal (Table 4).

Table 4: Post-operative pain relief score.

\begin{tabular}{|llll|}
\hline VAS score & $\mathbf{6}$ Weeks & $\mathbf{3}$ Months & $\mathbf{6}$ Months \\
\hline 0 (excellent) & 3 & 2 & 2 \\
\hline 1-2 (good) & 5 & 9 & 9 \\
\hline 3-4 (fair) & 4 & 0 & 1 \\
\hline$>$ 4 (poor) & 0 & 1 & 0 \\
\hline
\end{tabular}

In this study, $75 \%$ (9 patients) and 25\% (3 patients) were graded fair and poor respectively in the preoperative phase.

At 6 months, excellent results were obtained in 50\% (6 patients), good in $25 \%$ ( 3 patients), fair in $25 \%$ (3 patients), while none were graded as poor in terms of clinical evaluation (Table 5). 
Table 5: Clinical grading.

\begin{tabular}{|llll|}
\hline Grade & Functions & $\begin{array}{l}\text { Pre- } \\
\text { operative }\end{array}$ & $\begin{array}{l}\text { Post- } \\
\text { operative at } \\
\mathbf{6} \text { months }\end{array}$ \\
\hline \multirow{5}{*}{ Good } & $\begin{array}{l}\text { Pain-free, } \\
\text { normal } \\
\text { function of } \\
\text { part }\end{array}$ & 0 & 6 \\
& $\begin{array}{l}\text { Pain-free, } \\
\text { some } \\
\text { functional } \\
\text { impairment }\end{array}$ & 0 & \\
\hline Fair & $\begin{array}{l}\text { Pain with or } \\
\text { without } \\
\text { disability, } \\
\text { some } \\
\text { functional } \\
\text { impairment }\end{array}$ & 3 \\
\hline Poor & $\begin{array}{l}\text { Poor } \\
\text { disability } \\
\text { with severe } \\
\text { complication }\end{array}$ & 3 \\
\hline
\end{tabular}

\section{DISCUSSION}

In the prospective study, out of 7 cases of spinal fusion, 3 cases were of unstable vertebral fractures. Each of these T12, L1 and L4 fracture cases were treated by pedicle screw fixation and interlaminar and intertransverse fusion by structural and morselized allograft. There was one case of cervical myelopathy C3-4-5 in which expansive double 'French' door laminoplasty was done where allograft was placed in between the split spinous processes. Spinal fusion was also done in one case of L4- L5 and L5-S1 spondylolisthesis and one child of healed tuberculosis T12-L1 with a kyphotic deformity who underwent an instrumented posterior spinal fusion and one case of spinal tuberculosis requiring second stage anterior interbody fusion of L2-3.

Bone allografts were used in four cases of limb fractures. Two cases each were of 4 weeks old comminuted intertrochanteric fracture femur. In one case of depressed tibial plateau fracture, structural bone allograft was used to elevate the depressed fracture fragment to maintain articular integrity. One case of nonunion fracture neck of the femur with implant failure required revision of the implant with valgus osteotomy and bone allograft. On follow up, this patient had a recurrence of failure of the new implant with the persistence of nonunion of the fractured neck of femur.

It has been amply demonstrated that inadequate vascularity of the graft bed and instability of the bone graft in the host bed leads to the development of granulation tissue and fibrosis at the interface of the graft and host, precluding graft incorporation. ${ }^{8}$
Shukla et al reported complete consolidation in 26 out of 32 cases $81.25 \%$ of the patients and non-union in three cases $9.38 \%$ with no incidence of disease transmission during the study. ${ }^{9}$ Roudbariet al in 2015 showed $96.6 \%$ of success in graft after the duration of 6 months postoperatively. ${ }^{10}$ Mankin et al reported allograft replacement from November 1971 to January 1993 with a nonunion rate of $17 \% .^{11}$

Radiological incorporation of allograft was assessed by serial follow-up of anteroposterior and lateral roentgenograms at 6 weeks, 3 months, and 6 months, after the operation and CT-scan at 6 months follow up. Union was considered complete when either the delineated trabeculae bridging the graft host junction is visible, or the incorporated cancellous graft has acquired the same radiodensity as the supporting host bed, with continuous pattern throughout. ${ }^{12}$

A study report by Shukla et al showed complete consolidation in $80 \%$ of the patients within an average time of 30 weeks (range 12-72 weeks). ${ }^{9}$ Sethi et al in 1993, using demineralized bone, have reported the time required for consolidation to be six-nine months in children and nine-fifteen month in adults. ${ }^{13}$ Goel et al in 1992, using demineralized bone, observed consolidation in three months for simple bone cyst, four months for aneurysmal bone cyst and six-nine months for giant cell tumors. ${ }^{14}$

Bone allografts frequently get incorporated in the host bone and, when successful, represent as a permanent implant rather than a temporary spacer, with the primary benefit of normal reconstitution of normal or near-normal osseous architecture. ${ }^{15}$

In our study, out of 12 cases, only one case $8.33 \%$ got infected. This was a case of lumbar canal stenosis with spondylolisthesis L4-L5 and L5-S1 who underwent spinal decompression by hemilaminectomy at L4-L5 on the left side and bilateral extended fenestration at L3-L4 and L5S1 with pedicle screw fixation. In this case, intertransverse fusion with morselized allograft and interlaminar fusion with a structural bone allograft at L4-5 hemilaminectomy site was attempted. The duration of the primary surgery of this patient was prolonged (6.5 hours) and the intra-operative blood loss was $3000 \mathrm{ml}$. However, the postoperative period was uneventful and she was discharged after the usual 3 days. The infection was detected when she came for suture removal at 2 weeks. There was pus discharge from the operative site and the patient had been febrile for 3 days before that. The ESR was $60 \mathrm{~mm}$. at the end of 1 hour, the CRP was 20.1 and the contrast-enhanced MRI suggestive of a loculated collection of pus (approximately $5 \times 2.5 \mathrm{~cm}$ ) in the posterior soft tissue around the spinous process extending from L3 to L5 vertebra. The TC99m-ubiqucidin scintigraphy was suggestive of an active infectious focus involving the soft tissue around the lumbar vertebrae. The swab culture report of the donor head of the femur used as bone allograft in this patient showed no growth. 

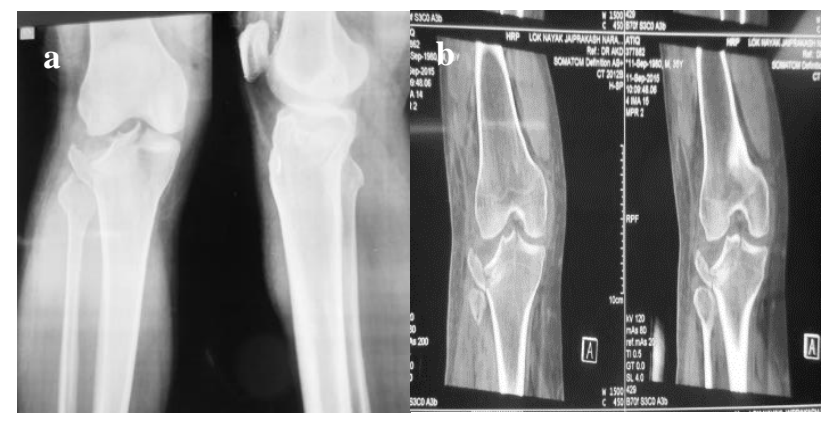

Figure 2: (a) Pre-operative X-ray and (b) preoperative CT scan showing depressed and split fracture of lateral condyle.

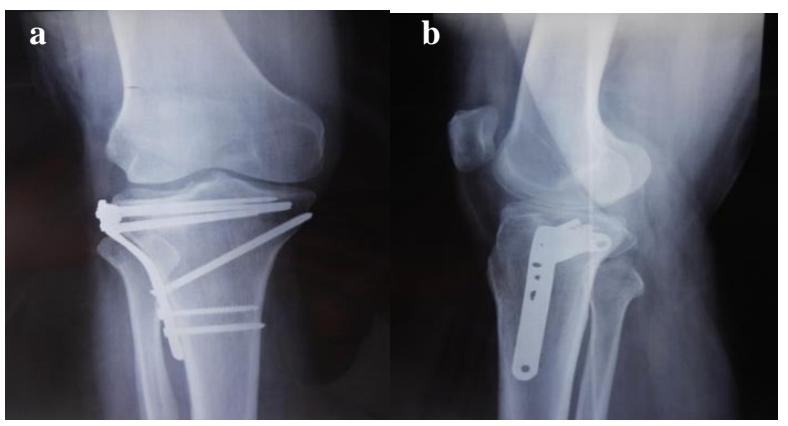

Figure 3 (a and b): Post-operative X-ray AP/lateral views at 6 months after bone grafting and plate fixation.

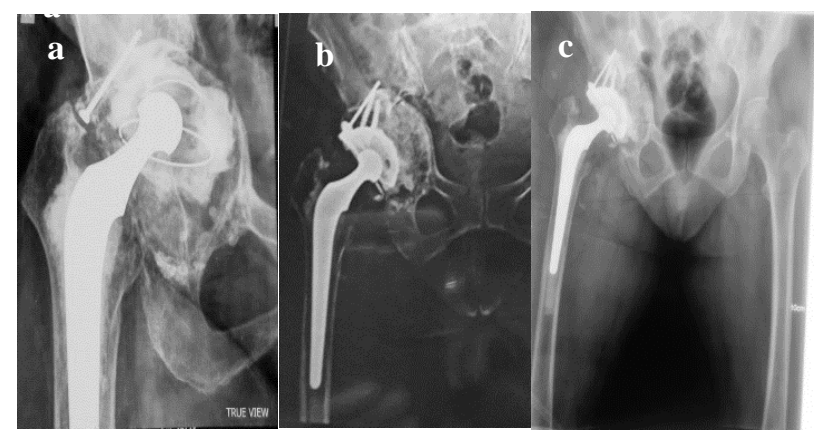

Figure 4: (a) Pre-operative X-ray of a failed THR showing a failed and mal positioned acetabular cup,

(b) post-operative $\mathrm{X}$-ray (at 3 months) of revision

THR (4 head of the femur and 1 TKR slice used), and

(c) post-operative $\mathrm{X}$-ray (at 6 months) of revision

THR showing good integration of the impacted morselized allograft in the cavitatory acetabular defect.

This infected surgical site was debrided with a thorough lavage along with the removal of all the pieces of the bone allografts. The intraoperative deep tissue pus culture report showed no growth of any organism and the biopsy report was acute on chronic inflammation. Subsequently, the wound healed satisfactorily within 4 weeks with no recurrence of infection.

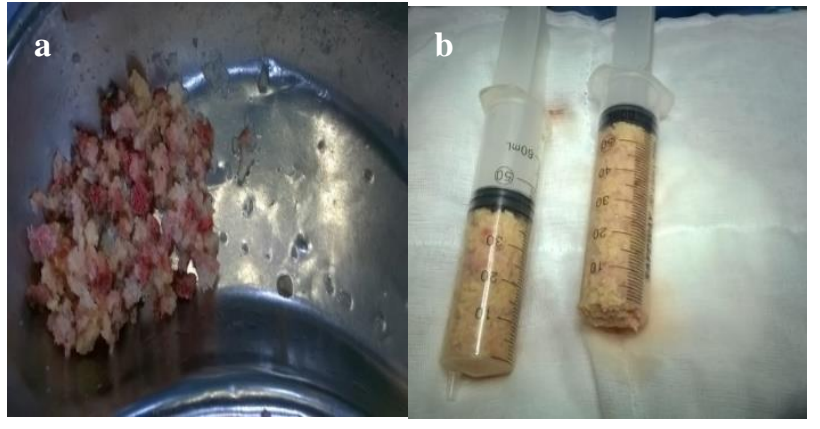

Figure 5: (a) Morselized piece of bone obtained from one femoral head and (b) morselized bone used in the syringe for injection into the bony cavity.

Showing preparation of allograft.

The incidence of postoperative infection in orthopedic surgery worldwide is 2.6 to $41.9 \% .^{16}$ Factors leading to higher infection rates include prolonged surgery. ${ }^{17}$ These statistical figures are similar to the single case of infection $8.33 \%$ we encountered in our series. Wu et al reported an overall allograft-associated infection rate of $1.2 \%$ $(24 / 2024) .{ }^{18}$ Sethi et al have reported an infection rate of $15 \%$ using demineralized bone grafts. ${ }^{13}$ Goel et al have reported an infection rate of $14.5 \%$ using demineralized bone grafts. ${ }^{14}$ Mankin et al have reported an infection rate of $13 \% .{ }^{19}$ A study report by Shukla et al showed one case of deep tissue infection $3.12 \%$ out of 32 cases. ${ }^{9}$ Lord et al have reported an infection rate of $11.1 \%$ using massive bone allograft and gram-positive (Staphylococcus epidermidis) was found to be the most common cause of infection. $^{20}$

An infection rate of $11 \%$ was reported by Mankin et al in the long term results of allograft replacement in the management of bone tumors from November 1971 to January 1993. ${ }^{11}$ Chang et al identified a $2.2 \%$ contamination rate for allografts retrieved from living donors when using bone swab cultures, and a contamination rate of $2.6 \%$ was described by Tomford et al using bone swab cultures from allografts donations. ${ }^{21,22}$ Sommerville et al reported a much higher allograft contamination rate of $22 \%$, using bone culture swabs and bone biopsy. ${ }^{23}$

In our study, prophylactic intravenous antibiotic cefazolin was used in all recipients and bone allografts donors. Chang at el reported that femoral heads harvested during hip arthroplasty surgery contain antibiotic cefazolin, and the morselized allografts could release cefazolin for up to 4 days, potentially exerting inhibitory effects against bacterial growth and colonization. ${ }^{21}$ Cunha at el reported therapeutic penetration of the antibiotic 'cefazolin' in most tissues, including the bones in patients undergoing total hip replacement. ${ }^{24}$

In this study, the mean ESR value of the cases was 16.75 preoperatively and 13.2 at the end of 6 months. Similarly, mean CRP pre-operatively was 6.82 and was 5.16 at 6 months. 
In our study, the case which got infected had elevated ESR and CRP values of 20 and 7.2 respectively on the second post-op day but on the 14th day at the time of infection the ESR and CRP values significantly increased to 60 and 20.1. The patient's wound healed at 4 weeks with no clinical signs of infection. In this case, there was a sequential successive decrease in the values of ESR and CRP at 6 weeks (ESR-38, CRP-16.4), 3 months (ESR-32, CRP-12.8), and 6 months (ESR-22, CRP-1.5). The repeat contrast-enhanced MRI done after 6 months of infection suggested no evidence of active infection. The study report by Kong at el showed significant abnormal values of CRP and ESR during the early postoperative period. ${ }^{25}$ Their results of anterior cervical fusion using allograft suggested that abnormal values of CRP and ESR in the early postoperative period do not indicate acute postoperative infection. Apart from the normal course, a second rise or more importantly, failure of decrease of CRP and ESR served as a signpost of acute postoperative infection. A study report by Larsson at el showed a similar trend of ESR and CRP postoperatively after elective orthopedic surgeries. ${ }^{26}$

Clinical grading was divided into four groups (modified Enneking grades) taking into consideration parameters like motion, pain, stability, functional activity. ${ }^{27,28}$

In this study, $75 \%$ ( 9 patients) and $25 \%$ (3 patients) were graded fair and poor respectively in the preoperative phase, the results were strikingly different at the follow-up period of 6 months postoperatively. At 6 months, excellent results were obtained in 50\% (6 patients), good in $25 \%$ (3 patients), fair in $25 \%$ (3 patients), while none were graded as poor in terms of clinical evaluation (Table 5). This result is comparable to the study report by Shukla et al were in $84 \%$ of the patients achieved excellent or good results. ${ }^{9}$ Mankin et al in 1987 reported $71 \%$ satisfactory (excellent and good) results for their series. ${ }^{29}$ According to them, the first and most important factor affecting the outcome is the effect of complications on the procedure. Mankin et al in1996 reported satisfactory (excellent and good) results between $70-80 \% .^{11}$

\section{CONCLUSION}

The concern about transmission of infection using fresh frozen bone allograft was laid to rest as there was no evidence of infection of the donor graft material. There was one case of post-operative infection similar to the incidence in any post-operative case series. Therefore, proper storage of fresh frozen bone allograft at $-70^{\circ}$ freezer, aseptic practices, better control of infection in the operation theatre, use of antibiotics judiciously resulted in an excellent outcome.

\section{Funding: No funding sources Conflict of interest: None declared \\ Ethical approval: The study was approved by the institutional ethics committee}

\section{REFERENCES}

1. Alencar DPG, Vieira IF. Bone banks. Rev Bras Ortop. 2015;45(6):524-8.

2. Friedlander GE. Bone banking in support of reconstructive surgery of the hip. Clin Orthop Relat Res. 1987;225:17-21.

3. Friedlander GE. Bone Grafts - the basic science rationale of clinical application. J Bone Joint Surg Am. 1987;69(5):786-90.

4. Malinin TI, Martinez OV, Brown MD. Banking of Massive Osteoarticular and intercalary bone allografts - 12 years' experience. Clin Orthop Relat Res. 1985;197:44-57.

5. Malenin TI, Wagner JL, Pito J, Lo H. Hypothermic Storage and cryopreservation of cartilage - an experimental study. Clin Orthop Relat Res. 1985;197:15-26.

6. Tomford WW, Mankin HJ, Friedlander GE, Doppelt S, Gebherdt MC. Methods of banking bone and cartilage for allograft transplantation. Orthop Clin North Am. 1987;18(2):241-7.

7. Goldberg VM, Stevenson S. Natural history of Autografts. Clin Orthop Relat Res. 1987;225:7-16.

8. Bauer TW, Muschler F. Bone graft material, an overview of the Basic Science. Clin Orthop. 2000;371:10-27.

9. Shukla S, Malhotra R, Bhan S. Results of fresh frozen bone allografts in orthopaedics. Indian J Orthop. 2003;37:8.

10. Roudbari S, Sami HAS, Roudbari M. The clinical results of benign bone tumor treatment with allograft or autograft. Arch Iran Med. 2015;18(2):109-13.

11. Mankin HJ, Gebhardt MC, Jennings LC, Springfield DS, Tomford WW. Long term Results of Allograft replacement in the management of bone tumors. Clin Orthop. 1996;324:86-97.

12. Conn RA, Paterson LFA, Stauffer RN, Ilstrup D. Management of acetabular deficiency. Long term results of bone grafting of acetabulum in THR. Orthop Trans. 1985;9:451-2.

13. Sethi A, Aggarwal K, Tulsi SM, Sethi S, Kumar S, Maurya SK. Allografts in treatment of Benign Cystic Lesions of Bone. Arch Orthop Trauma Surg. 1993;112(4):167-70.

14. Goel SC, Tuli SM, Singh HP, Sharma SV, Saraf SK, Srivastava TP. Allogenic decalcified Bone in Repair of Benign Cystic lesions of Bone. Int Orthop. 1992;16(2):176-9.

15. Borja FJ, Mnaymneh W. Bone allografts in salvage of difficult hip arthroplasties. Clin Orthop. 1985;197:23.

16. Mulhim AFA, Baragbah MA, Ali SM, Alomran AS, Azam MQ. Prevalence of Surgical Site Infection in Orthopedic Surgeries, 5 years analysis. Int Surg. 2014;99(3):264-8.

17. Peersman G, Laskin R, Davis J, Peterson GE, Richart T. Prolonged Operative Time Correlates with Increased Infection Rate after Total Knee Arthroplasty. HSS J. 2006;2(1):70-2. 
18. Wu C, Hsieh P, Jiang JF, Shih H, Chen C, Hu C. A positive bacterial culture from allograft bone at implantation does not correlate with subsequent surgical site infection. J Bone Joint. 2015;97:427-31.

19. Mankin HJ, Doppelt S, Tomford W. Clinical experience with allograft implantation, the first ten years. Clin Orthop. 1983;174:69-86.

20. Lord CF, Gebhardt MC, Tomford WW, Mankin HJ. Infection in bone allografts. Incidence, nature, and treatment. J Bone Joint Surg Am. 1988;70(3):369-76.

21. Chang Y, Shih HN, Chen DW, Lee MS, Ueng SW, Hsieh PH. The concentration of antibiotics in freshfrozen bone allograft. J Bone Joint Surg Br. 2010;92:1471-4.

22. Tomford WW, Ploetz JE, Mankin HJ. Bone allografts of femoral heads - procurement and storage. J Bone Joint Surg Am. 1986;68(4):534-7.

23. Sommerville SM, Johnson N, Bryce SL, Journeaux SF, Morgan DA. Contamination of banked femoral head allograft: incidence, bacteriology and donor follow up. Aust N Z J Surg. 2000;70:480-4.

24. Cunha BA, Gossling HR, Pasternak HS, Nightingale $\mathrm{CH}$, Quintiliani R. The penetration characteristics of cefazolin, cephalothin, and cephradine into bone in patients undergoing total hip replacement. J Bone Joint Am. 1977;59:856-9.

25. Kong CG, Kim YY, Park JB. Post-operative changes of early-phase inflammatory indices after uncomplicated anterior cervical discectomy and fusion using allograft and demineralised bone matrix. Int Orthop. 2012;36(11):2293-7.

26. Larsson S, Thelander U, Friberg S. C-reactive protein (CRP) levels after elective orthopedic surgery. Clin Orthop Relat Res. 1992;275:237-42.

27. Kubosch EJ, Bernstein A, Wolf L, Fretwurst T, Nelson K, Schmal H. Clinical trial and in-vitro study comparing the efficacy of treating bony lesions with allografts versus synthetic or highly-processed xenogeneic bone grafts. BMC Musculoskelet Discord. 2016;17:118.

28. Enneking WF, Spanier SS, Goodman MA. Current concept review: The surgical staging of musculoskeletal sarcoma. J Bone Joint Surg Am. 1989;62A:1027-30.

29. Mankin HJ, Gebherdt MC, Tomford WW. The use of frozen cadaveric allografts in the management of patients with bone tumors of the extremities. Orthop Clin North Am. 1987;18(2):275-90.

Cite this article as: Jajoriya LN, Sural S.

Evaluation of incorporation of bone allograft at the site of implantation in various clinical conditions along with its complications. Int J Res Orthop 2020;6:760-6 